\title{
Janusz Zeyland w świetle wspomnień Wiktora Degi
}

\section{Janusz Zeyland in the light of the memoirs of Wiktor Dega}

\author{
Anita Magowska ${ }^{1}$
}

Poznań

Streszczenie: Janusz Zeyland (1897-1944) był wybitnym pediatrą i mikrobiologiem, znawca gruźlicy dziecięcej i pionierem szczepień przeciwgruźliczych w Polsce. W czasie Powstania Warszawskiego został zastrzelony przez Niemców w szpitalu, w którym pracował. Krótki artykuł przedstawia nieznane fakty z życia Zeylanda na podstawie wspomnień jego przyjaciela, Wiktora Degi, zasłużonego dla rozwoju ortopedii i medycyny rehabilitacyjnej w Polsce.

Abstract: Janusz Zeyland (1897-1944) was an outstanding paediatrician and microbiologist, an expert of children's tuberculosis and a pioneer of BCG vaccination in Poland. During the Warsaw Uprising he was shot dead by Germans at the hospital, in which he worked. This article is presenting so far undisclosed facts from the Zeyland's life. It is based on memoires of his friend, Wiktor Dega (1896-1995), a Polish distinguished orthopaedist and rehabilitation medicine specialist.

Słowa kluczowe: Janusz Zeyland, Wiktor Dega, historia gruźlicy

Keywords: Janusz Zeyland, Wiktor Dega, history of tuberculosis

Życie Janusza Zeylanda (1897-1944), wybitnego znawcy gruźlicy dziecięcej i pioniera szczepień BCG w Polsce, jest znane przede wszystkim dzięki wspomnieniom Karola Jonschera ${ }^{2}$ i Zbigniewa Woźniewskiego ${ }^{3}$ oraz opartym o nie biogramom i artykułom biograficznym ${ }^{4}$. Dosyć oficjalny wizerunek poznańskiego uczonego ocieplaja wspomnienia Wiktora Degi (1896-1995) i pochodzace z jego spuścizny fotografie ze zbiorów Katedry i Zakładu Historii i Filozofii Nauk Medycznych Uniwersytetu Medycznego im. Karola Marcinkowskiego. W 1985 r. wspomnienia Degi zostały opublikowane w „Kwartalniku Historii Nauki i Techniki” ${ }^{\prime}$, a w 2000 r. w serii Biblioteka

Uniwersytet Medyczny w Poznaniu.

2 K. Jonscher, Śp. prof. dr Janusz Zeyland (1897-1944), “Nowiny Lekarskie” 1946, nr 5, s. 85-87.

3 Z. Woźniewski, Prof. dr med. Janusz Zeyland jako ordynator Szpitala Wolskiego w Warszawie, „Polski Tygodnik Lekarski" 1946, nr 13, s. 393-396.

4 Np.: R. Meissner, Zeyland Janusz, [w:] WSB, red. Antoni Gąsiorowski, Warszawa Poznań 1981, s. 871-872.

5 W. Dega, Zapiski do autobiografii, cz. 1, Moja droga życiowa do wiedzy i zawodu, „Kwartalnik Historii Nauki i Techniki" 1985, s. 259-322. 
Prac Historycznych Akademii Medycznej im. Karola Marcinkowskiego w Poznaniu', jednak dotychczas nie dostrzeżono, że prostują niektóre błędy biografów Zeylanda, np. że został ciężko ranny podczas wojny polsko-bolszewickiej, albo że został odkomenderowany na studia lekarskie na Uniwersytecie Warszawskim?

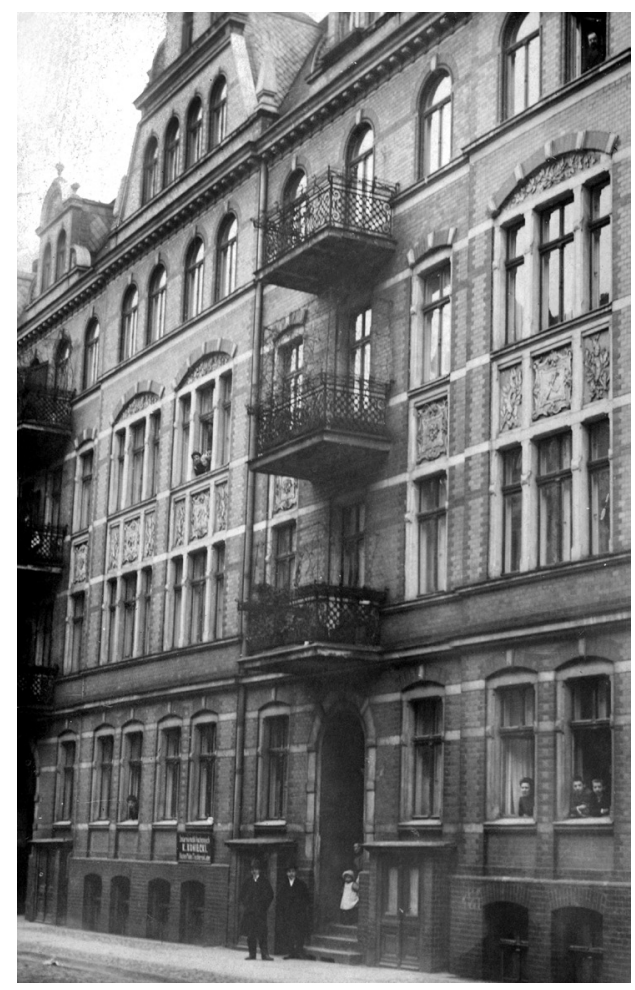

Ryc. 1. Kamienica, w której mieszkał Janusz Zeyland przy ul. św. Piotra, obecnie Krysiewicza (zbiory Katedry i Zakładu Historii i Filozofii Nauk Medycznych Uniwersytetu Medycznego w Poznaniu)

„Był to mój najserdeczniejszy przyjaciel i przez długie lata łączyły nas wspólne przeżycia" - pisał o nim Wiktor Dega, twórca poznańskiej szkoły ortopedii i pionier medycyny rehabilitacyjnej ${ }^{8}$. Urodzony w $1897 \mathrm{r}$. Zeyland był od niego o rok młodszy. Mieszkali w tej samej kamienicy przy ul. Św. Piotra (obecnie ul. Krysiewicza) w Poznaniu, naprzeciw szpitala dziecięcego, którego założyciel, dr Bolesław Krysiewicz, był lekarzem domowym rodziny Degów. Razem spędzali czas jako dzieci, a potem uczyli

${ }_{6}$ Retrospekcje Wiktora Degi, [w:] Wiktor Dega znany i nieznany, oprac. Irena Stasiewicz-Jasiukowa, Biblioteka Prac Historycznych Akademii Medycznej im. Karola Marcinkowskiego w Poznaniu, Seria A: Monografie, t. 3, Poznań 2000.

7 W. Lisowski, Prekursorzy medycyny polskiej, t. 2, Warszawa 2012, s. 464.

8 Retrospekcje Wiktora Degi..., s. 60. 
się w tym samym Gimnazjum Marii Magdaleny. Lekcje odbywały się po niemiecku, ale podczas przerw na szkolnych korytarzach królował język polski, bo większość uczniów stanowili Polacy. Potrzeba poznawania języka polskiego i historii Polski skłoniła Zeylanda i Degę do uczęszczania na lekcje polskiego i historii do pani Rakowskiej na pobliską ul. Półwiejska.

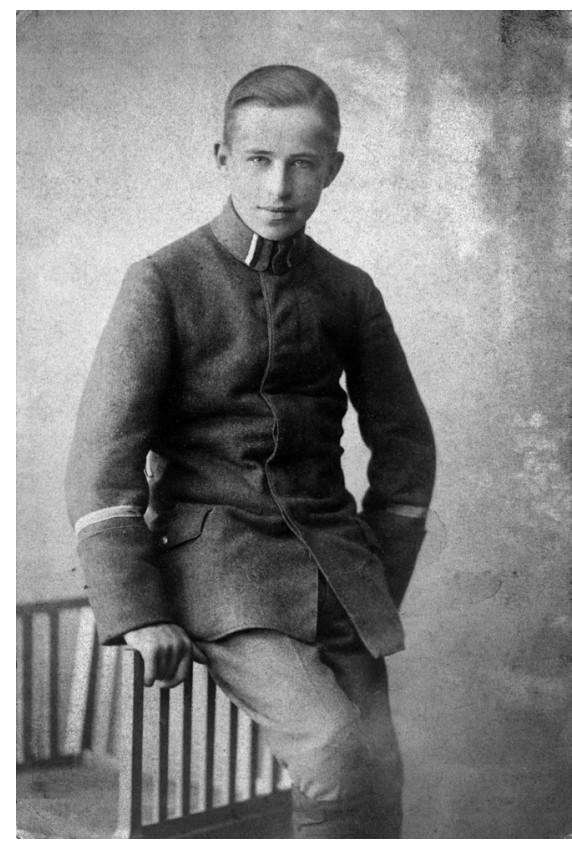

Ryc. 2. Janusz Zeyland jako gimnazjalista

(zbiory Katedry i Zakładu Historii i Filozofii Nauk Medycznych Uniwersytetu Medycznego w Poznaniu)

W 1913 r. obaj zapisali się do drużyny skautów prowadzonej przez tajne Towarzystwo im. Tomasza Zana. Rok później, przekonani o rychłym wybuchu wojny, która miała przynieść Polsce niepodległość, w tajemnicy przed rodzicami razem wstapili do paramilitarnej Tajnej Organizacji Niepodległościowej. Tam nauczyli się musztry, regulaminów wojskowych i obsługi karabinu maszynowego, podarowanego przez galicyjską organizację strzeleckạ.

W maju 1917 r. Zeyland ukończył gimnazjum i został immatrykulowany na Wydziale Lekarskim Uniwersytetu Berlińskiego, ale nauki nie zdołał rozpocząc, ponieważ został wcielony do armii niemieckiej. Służbę zakończył na początku grudnia 1918 r. Po powrocie do Poznania ponownie włączył się w działalność Tajnej Organizacji Niepodległościowej. Został przydzielony do eskorty, która 26 grudnia chroniła przed rozentuzjazmowanym tłumem powóz wiozący Ignacego Paderewskiego z dworca kolejo- 
wego do hotelu Bazar. Noc spędził w holu Muzeum Wielkopolskiego ${ }^{10}$, nadal strzegac Paderewskiego ${ }^{11}$.

Następnego dnia wybuchło Powstanie Wielkopolskie, a kolejnego Zeyland i Dega wstapili jako ochotnicy do wojska polskiego i uczestniczyli w walkach o pruskie magazyny wojskowe przy ul. Artyleryjskiej, a potem o Stary Rynek, . Zostali ulokowani w koszarach przy ul. Bukowskiej i przydzieleni do 1 Pułku Strzelców Wielkopolskich ${ }^{12}$, który walczył o Urząd Pocztowy przy Dworcu Zachodnim i lotnisko na Ławicy, a na poczatku maja 1919 r. został wysłany na front północny wojny polsko-bolszewickiej. Po miesiącu Zeyland wraz ze swoim Pułkiem wyruszył na odsiecz Lwowowi, a w sierpniu tego roku wrócił do Poznania.

W ówczesnej sytuacji politycznej Polski zwolnienie ze służby wojskowej było niemożliwe, dlatego wraz z Degą rozpoczął starania o trzymiesięczny urlop na przeszkolenie lekarskie. Razem wyjechali do Warszawy i zamieszkali w bardzo skromnych warunkach przy ul. Ordynackiej 13. W styczniu 1920 r. Zeyland rozpoczałł studia na Wydziale Lekarskim Uniwersytetu Warszawskiego. Był wojskowym, dlatego zaliczono mu pierwszy trymestr jako semestr, ale w lipcu 1920 r. Zeyland znów został wysłany na front wschodni wojny polsko-bolszewickiej. Dostał się do niewoli rosyjskiej, z której został zwolniony w marcu 1921 r. jako inwalida. Jego koń przewrócił się przygniatając go i powodując złamanie szyjki kości udowej. Korzystając z aparatu ortopedycznego odciążającego złamane miejsce i umożliwiającego poruszanie się, Zeyland ukończył kolejny trymestr na Uniwersytecie Warszawskim, jednak szyjka kości udowej nie zrastała się i poruszał się z trudem. Latem 1921 r. poddał się operacji, która przeprowadził kierownik Kliniki Ortopedycznej Uniwersytetu Poznańskiego prof. Ireneusz Wierzejewski, a której przypatrywał się Wiktor Dega. Posługujac się innowacyjna wtedy technika, Wierzejewski wykonał przeszczep kostny materiałem pobranym z kości piszczelowej. Złamana kość została wzmocniona i zrosła się. Wyzwolenie z aparatu ortopedycznego i odzyskana swoboda poruszania były źródłem wielkiej radości Zeylanda ${ }^{13}$. Nawiązany wtedy kontakt z prof. Wierzejewskim pomógł Dedze w uzyskaniu po studiach asystentury w jego klinice ${ }^{14}$.

Zeyland zaliczył rok akademicki 1921/1922, podobnie jak Dega, w Warszawie. Dodatkowo pracował jako wolontariusz w Zakładzie Histologii i Embriologii kierowanym przez prof. Mieczysława Konopackiego ${ }^{15}$. Trudności materialne sprawiły, że na ostatnie dwa lata jednak przeniósł się wraz z przyjacielem na Uniwersytet Poznański, na którym już uruchomiono wszystkie wymagane zajęcia kliniczne ${ }^{16}$. Z zachowanych fotografii z tego okresu wynika, że Zeyland umiał rysować. Zdarzyło się podczas

10 Jest to dzisiejszy gmach Muzeum Narodowego przy Alejach Marcinkowskiego.

11 Retrospekcje Wiktora Degi..., s. 62.

12 Z czasem został przemianowany na 10 Pułk Strzelców Wielkopolskich.

13 Retrospekcje Wiktora Degi..., s. 64-65.

14 Tamże, s. 67.

15 Z. Woźniewski, Prof. dr med. Janusz Zeyland..., s. 393.

16 Retrospekcje Wiktora Degi..., s. 64-65. 


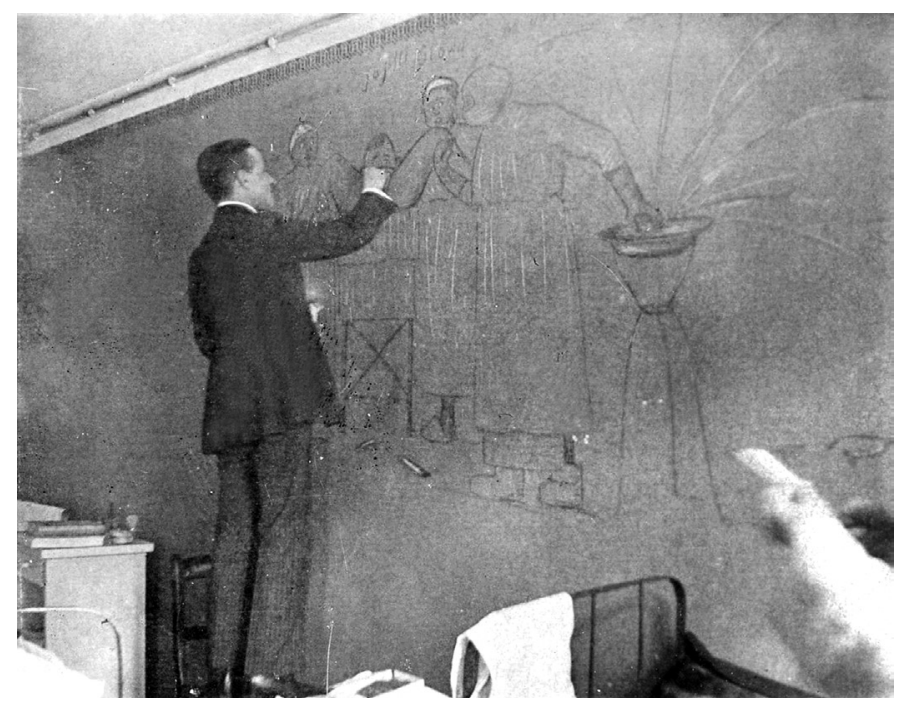

Ryc. 3. Janusz Zeyland rysuje karykaturę na ścianie szpitala przy ul. Polnej, 1923 rok (zbiory Katedry i Zakładu Historii i Filozofii Nauk Medycznych Uniwersytetu Medycznego w Poznaniu)

praktyk studenckich z położnictwa, że swoimi karykaturami ozdobił szpitalne ściany. Mimo ciężkich wojennych przeżyć, cechowała go młodzieńcza potrzeba żartów.

W 1924 r. Zeyland uzyskał dyplom doktora wszech nauk lekarskich i został asystentem w kierowanym przez prof. Ludwika Skubiszewskiego Zakładzie Anatomii Patologicznej UP. Jedna z jego pierwszych prac badawczych została wykonana z inspiracji Wiktora Degi i przy jego współudziale. Amputacja była wtedy jedyną metoda postępowania chirurgicznego wobec kończyny zajętej guzem olbrzymiokomórkowym. Pacjentem Degi był kilkuletni chłopiec cierpiący na tę chorobę. Jego ojciec nie wyraził zgody na amputację, dlatego Dega usunął jedynie guz, a powstały ubytek kości uzupełnił przeszczepami kostnymi. Dziecko wyzdrowiało, dlatego Dega poprosił Zeylanda o wykonanie badania histopatologicznego guza. Okazało się, że komórki olbrzymie nie wykazują cech złośliwości. Zaintrygowany Zeyland odszukał w zbiorach zakładowego muzeum anatomopatologicznego wszystkie słoje z preparatami pochodzacymi z amputacji i opisanymi jako guz olbrzymiokomórkowy, dowodząc, że większość amputacji wykonano zbytecznie. Zeyland opublikował na ten temat wspólną pracę z Degą i samodzielnie napisany artykuł ${ }^{17}$.

Na tym kończą się wątki dotyczące Janusza Zeylanda zawarte we wspomnieniach Degi. Z kolei okoliczności jego śmierci utrwaliła swym piórem Maria Deżyna, żona wybitnego poznańskiego ortopedy:

5 października mieliśmy nieoczekiwana wizytę. Przyszły panie dr Kurowska i pani Miki, współpracowniczki Ojka w Szpitalu Karola i Marii. (...) Niestety potwierdziły one 


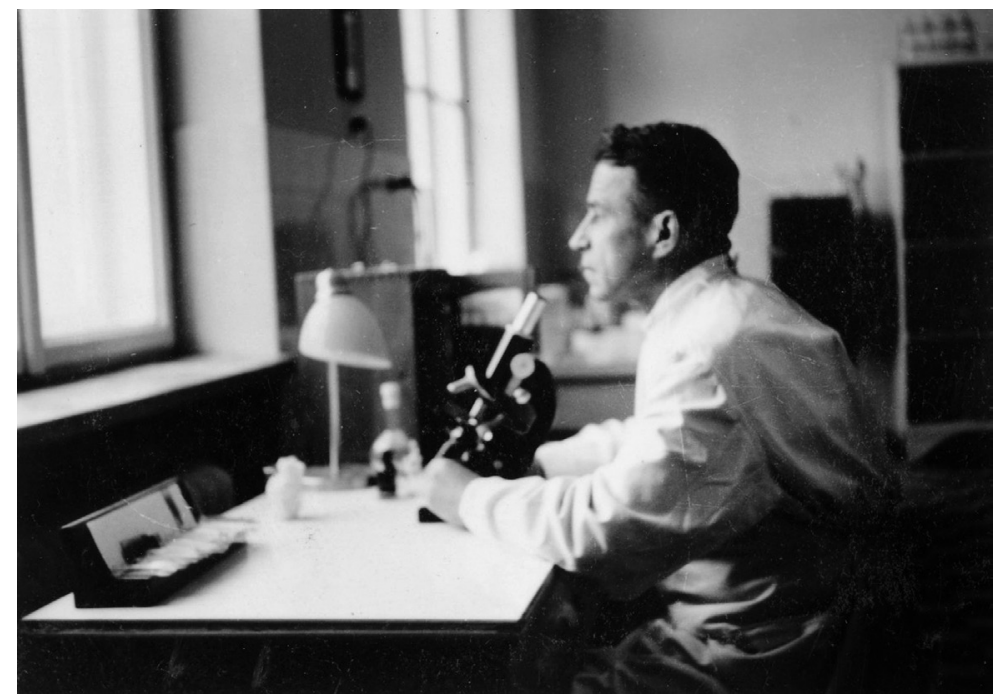

Ryc. 4. Janusz Zeyland w Zakładzie Anatomii Patologicznej UP, 1925 rok (zbiory Katedry i Zakładu Historii i Filozofii Nauk Medycznych Uniwersytetu Medycznego w Poznaniu)

wiadomość, że Janusz nie żyje. Kiedy Powstanie się zaczęło, pozostał w Szpitalu Wolskim, by służyć za tłumacza. Kiedy horda niemiecka weszła 5 sierpnia do szpitala, w pokoju dyrektora był także dyrektor, kapelan i Janusz Zeyland. Bez słowa ich rozstrzelali. Potem zjawił się jakiś tam wyższy szarżą Niemiec i stwierdził: Zeyland? Ach, ten nie miał być zastrzelony!" 18 .

\section{Wykaz literatury:}

1. Dega M., Dni dobre i złe. 1906-1996, Warszawa 1970, s. 180.

2. Dega W., Zapiski do autobiografii, cz. 1, Moja droga życiowa do wiedzy i zawodu, „Kwartalnik Historii Nauki i Techniki" 1985, s. 259-322.

3. Jonscher K., Śp. prof. dr Janusz Zeyland (1897-1944), „Nowiny Lekarskie” 1946, nr 5, s. 85-87.

4. Lisowski W., Prekursorzy medycyny polskiej, t. 2, Warszawa 2012, s. 464.

5. Meissner R, Zeyland Janusz, [w:] WSB, red. Antoni Gąsiorowski, Warszawa Poznań 1981, s. 871-872.

6. Retrospekcje Wiktora Degi, [w:] Wiktor Dega znany i nieznany, oprac. Irena Stasiewicz-Jasiukowa, Biblioteka Prac Historycznych Akademii Medycznej im. Karola Marcinkowskiego w Poznaniu, Seria A: Monografie, t. 3, Poznań 2000.

7. Woźniewski Z., Prof. dr med. Janusz Zeyland jako ordynator Szpitala Wolskiego w Warszawie, „Polski Tygodnik Lekarski" 1946, nr 13, s. 393-396. 